\title{
Effects of chronic exposure to clothianidin on the earthworm Lumbricus terrestris
}

\author{
Kate Basley ${ }^{\text {Corresp., }}{ }^{1}$, Dave Goulson ${ }^{1}$ \\ ${ }^{1}$ School of Life Sciences, University of Sussex, Brighton, East Sussex, United Kingdom \\ Corresponding Author: Kate Basley \\ Email address: katebasley@gmail.com
}

Although neonicotinoids are targeted at insects, their predominant use as a seed dressing and their long persistence in soils mean that non-target soil organisms such as earthworms are likely to be chronically exposed to them. Chronic exposure may pose risks that are not evaluated in most toxicity tests. We experimentally tested the effect of field-realistic concentrations of a commonly used neonicotinoid, clothianidin, on mortality, weight gain, and food consumption to assess the impacts of chronic exposure over 4 months on fitness of $L$. terrestris individuals. We undertook three separate experiments, each with different exposure routes: treated soil only (experiment A), treated food and soil combined (experiment B) and treated food only (experiment C). Mortality was negatively affected by exposure from treated soil only with greatest mortality observed in the groups exposed to the two highest concentrations (20ppb and 100ppb), but no clear effect on mortality was found in the other two experiments. When clothianidin was present in the food, an antifeedant effect was present in months one and two which subsequently disappeared; if this occurs in the field, it could result in reduced rates of decomposition of treated crop foliage. We found no significant effects of any treatment on worm body mass. We cannot rule out stronger adverse effects if worms come into close proximity to treated seeds, or if other aspects of fitness were examined. Overall our data suggest that field-realistic exposure to clothianidin has a significant but temporary effect on food consumption and can have weak but significant impacts on mortality of $L$. terrestris. 
1 Effects of chronic exposure to clothianidin on the earthworm

2 Lumbricus terrestris

3

4

$5 \quad$ Kate Basley ${ }^{1}$ and Dave Goulson ${ }^{1}$

6 1. School of Life Sciences, John Maynard Smith Building, The University of Sussex, Falmer, East 7 Sussex, BN1 9QG, UK

8

9

10 K.Basley@sussex.ac.uk

11 D.Goulson@sussex.ac.uk

Corresponding author - Kate Basley

Competing interests: The authors have declared that no competing interests exist.

Key-words: neonicotinoid, clothianidin, chronic exposure, earthworms, food consumption, weight, 17 mortality, non-target 


\section{Abstract}

Although neonicotinoids are targeted at insects, their predominant use as a seed dressing and their long persistence in soils mean that non-target soil organisms such as earthworms are likely to be chronically exposed to them. Chronic exposure may pose risks that are not evaluated in most toxicity tests. We experimentally tested the effect of field-realistic concentrations of a commonly used neonicotinoid, clothianidin, on mortality, weight gain, and food consumption to assess the impacts of chronic exposure over 4 months on fitness of L. terrestris individuals. We undertook three separate experiments, each with different exposure routes: treated soil only (experiment A), treated food and soil combined (experiment B) and treated food only (experiment C). Mortality was negatively affected by exposure from treated soil only, with greatest mortality observed in the groups exposed to the two highest concentrations (20ppb and 100ppb), but no clear effect on mortality was found in the other two experiments. When clothianidin was present in the food, an anti-feedant effect was present in months one and two which subsequently disappeared; if this occurs in the field, it could result in reduced rates of decomposition of treated crop foliage. We found no significant effects of any treatment on worm body mass. We cannot rule out stronger adverse effects if worms come into close proximity to treated seeds, or if other aspects of fitness were examined. Overall our data suggest that field-realistic exposure to clothianidin has a significant but temporary effect on food consumption and can have weak but significant impacts on mortality of L. terrestris. 


\section{Introduction}

Neonicotinoids are the most widely used group of pesticides in the world (Jeschke et al., 2011). Their leaching potential and systemic properties mean that many non-target organisms in agricultural landscapes are likely to be exposed (Goulson 2013), and their current prophylactic use on many arable crops presents a potential for large scale contamination of non-target areas. Neonicotinoids are often applied as seed dressings (Jones, Harrington \& Turnbull, 2014), with typically $94 \%$ of the active ingredient applied to the crop seed entering the soil rather than the crop (Goulson, 2013). Residues of these compounds have been detected in soil more than three years after introduction via seed treatments (Botías et al., 2016). Clothianidin, a commonly used neonicotinoid, has a reported half-life of 148-1155 days in aerobic soil, potentially exposing soil-dwelling organisms such as earthworms for extended periods of time (Jones, Harrington \& Turnbull, 2014). It is this reported persistence that is amplifying the concern surrounding the impact of neonicotinoids on non-target organisms.

The application of agricultural products such as neonicotinoids for the protection of agricultural and horticultural crops has been shown to introduce these compounds to the drilosphere (the part of the soil which is influenced by earthworm secretions and castings), where the soil acts as a sink for agricultural products (Givaudan et al., 2014). Neonicotinoids can also compromise the function of soil organisms that contribute to soil fertility which may limit crop yield (Moffat et al., 2016). Their presence in the soil profile poses a hazard to resident worm populations, as the same neural pathways that are the target of neonicotinoids in pest species, are also present in earthworms (Volkov et al., 2007). Acting as Nicotinic Acetylcholine Receptor agonists, very low levels can significantly disrupt neural functioning in bees (Piiroinen et al., 2016), so if the negative effects of the neonicotinoid are similar to those for other non-target insects (Pisa et al., 2014), the worm's critically important role in the maintenance of soil properties could potentially be affected. Exposure can either be by direct physical contact with a treated seed or contaminated soil or soil water. Moreover, it is typical for earthworm species to ingest soil particles as they burrow, hence presenting an oral route of exposure to the compounds (Pisa et al., 2014). 
73 The majority of studies investigating the impact of neonicotinoids on earthworms have focused on Eisenia fetida, with the range of reported lethal concentrations based on this species and little consideration given to the sensitivities of other species (Pisa et al., 2014). E. fetida are compost worms, and so are not typically found in areas where neonicotinoids are in use, preferring warm and moist habitats with a ready supply of fresh compost material. They are also claimed to be less sensitive to environmental toxicants than other earthworm species (Dittbrenner et al., 2010), and so results from these test species provide little insight into the potential impact of pesticides on earthworms in arable ecosystems. A recent review exploring the biochemical and molecular markers as indicators of the accumulation of pollutants, specifically pesticides, reported varying levels of biomolecules in different parts of the earthworm which indicated varying sensitivity of earthworms to different xenobiotics (Tiwari et al., 2016).

L. terrestris is commonly found in grasslands and lawns, especially when the ground is left undisturbed (Sherlock 2012) and is more representative of species found on agricultural land and in field margin soils than E. fetida (Nuutinen, Butt \& Jauhiainen, 2011); its widespread geographical range and frequently high abundance make it a special target for concern and study, since it is likely to play a major role in contributing to soil health (Tomlin, 1992).

Anecic worm species such as $L$. terrestris live and feed on the soil and are of particular benefit to arable soils where worms can constitute up to $80 \%$ of total soil animal biomass (Pisa et al., 2014). Their wide and deep-penetrating burrows open up the structure of compacted and clayey soils by enabling water infiltration (Nuutinen, Butt \& Jauhiainen, 2011), and soil fertility is enhanced by the breakdown of plant litter and the mixing of this litter with the soil (Pisa et al., 2014). Physical disturbance of the soil by tillage and ploughing can have strong negative effects on the abundance of $L$. terrestris and so higher population densities are often found in field margins which may act as source areas for the worm, supporting population growth within the field (Nuutinen et al. 2011). As these worms feed at the soil surface they are likely to be exposed to higher concentrations of pesticides as agrochemical concentration is often higher at the soil surface (Chagnon et al., 2014).

To date, the few studies that have considered the impact of neonicotinoids on L. terrestris have focussed only on the neonicotinoid imidacloprid (Table 1). Studies showed little or no 
104 measurable impact on survival at 4ppm (Dittbrenner et al., 2012), but with a moderate decrease

105 in body mass and large decrease in cast production being observed at $0.66 \mathrm{ppm}$ (Dittbrenner et

106 al., 2010). Cast production was negatively affected at 0.66ppm and 0.189ppm (Capowiez et al., 107 2010). 
Table 1. Impact of neonicotinoid imidacloprid on L. terrestris. Lowest effective concentration is the lowest concentration at which a significant effect was reported. $0=$ little or no measurable effect, - = moderate decrease, -- =large decrease. Table adapted from Pisa et al. (2014).

\begin{tabular}{|c|c|c|c|c|}
\hline $\begin{array}{l}\text { Measured } \\
\text { endpoint }\end{array}$ & Impact & $\begin{array}{l}\text { Lowest } \\
\text { effective } \\
\text { concentration }\end{array}$ & $\begin{array}{l}\text { Duration of } \\
\text { exposure to } \\
\text { contaminant }\end{array}$ & Study \\
\hline $\begin{array}{l}\text { Survival } \\
\text { Avoidance }\end{array}$ & $\begin{array}{l}0 \\
0\end{array}$ & $\mathrm{~N} / \mathrm{A}$ & 14 days & $\begin{array}{l}\text { (Dittbrenner et al., } \\
\text { 2012) }\end{array}$ \\
\hline Burrowing & - & $2 \mathrm{ppm}$ & 7 days & $\begin{array}{l}\text { (Dittbrenner et al., } \\
\text { 2011) }\end{array}$ \\
\hline $\begin{array}{l}\text { Feeding } \\
\text { activity } \\
\text { Abundance }\end{array}$ & - & $43 \mathrm{mg} \mathrm{m}^{-2}$ & 6 weeks & (Tu et al., 2011) \\
\hline $\begin{array}{l}\text { Body mass } \\
\text { change } \\
\text { Cast } \\
\text { production }\end{array}$ & $\begin{array}{l}- \\
--\end{array}$ & $\begin{array}{l}0.66 \mathrm{ppm} \\
0.66 \mathrm{ppm}\end{array}$ & $\begin{array}{l}7 \text { days } \\
7 \text { days }\end{array}$ & $\begin{array}{l}\text { (Dittbrenner et al., } \\
2010 \text { ) }\end{array}$ \\
\hline $\begin{array}{l}\text { Cast } \\
\text { production } \\
\text { Body mass } \\
\text { change }\end{array}$ & - & $\begin{array}{l}1.89 \mathrm{ppm} \\
0.189 \mathrm{ppm}\end{array}$ & $\begin{array}{l}7 \text { days } \\
7 \text { days }\end{array}$ & $\begin{array}{l}\text { (Capowiez et al., } \\
\text { 2010) }\end{array}$ \\
\hline
\end{tabular}

112 The authors are aware of no published studies that have investigated the impact of chronic

113 exposure of clothianidin on L. terrestris. Clothianidin has recently become the most

114 commonly used neonicotinoid in the UK (Defra PUSSTATS), and is regularly used for seed,

115 foliar, and soil treatments (Jeschke et al., 2011). One study of agrochemical toxicity to $E$.

116 fetida found clothianidin to be the most toxic of 45 pesticides tested, with an LC50 value of

$1170.28 \mu \mathrm{g} \mathrm{cm}^{-2}$ from a filter paper contact test. When tested in artificial soil for 14 days,

118 clothianidin showed the highest intrinsic toxicity against E. fetida with an LC50 values of

1196.06 (5.60-6.77) $\mathrm{mg} \mathrm{kg}^{-1}$ (Wang et al., 2012). A recent review investigating the impact of

120 different types of neonicotinoids at varied concentrations on earthworm survival,

121 reproduction and behaviour was conducted across different types of earthworm species; Pisa

122 et al. (2014) concluded that individuals are at risk of mortality if they consume soil or organic

123 particles of about $1 \mathrm{ppm}$ for several days. It is possible that long-term low level concentration

124 of neonicotinoids in soil may pose a higher risk to earthworms from sub-lethal effects than

125 can be deduced from short-term toxicity tests, which typically last for a few days (Pisa et al. 
126 2014). Here, we experimentally test the effect of field-realistic doses of clothianidin on

127 mortality, weight gain, and food consumption to assess the overall impacts on fitness of

128 chronic exposure of L. terrestris individuals.

\section{Method}

130 Soil contamination

131 The soil moisture content of both a sharp sand and a sterilised Kettering loam was taken

132 using a TDRC 'FieldScout' soil moisture content probe. Kettering loam is used by many

133 researchers as a reliable earthworm culture substrate and has been proposed as a standard

134 medium for toxicology tests (Lowe \& Butt, 2005). The loam was mixed with a sharp sand to

135 make a more friable substrate. CLO stock solution (made up in water) was diluted as

136 appropriate with more spring water (ASDA, own brand), then mixed with sand and finally

137 loam to give a 70:30 loam : sand mix with a 25\% moisture content (Berry \& Jordan, 2001).

138 Treatment groups of $0 \mathrm{ppb}$ (control), 1ppb, 5ppb, 10ppb, and 20ppb were based on

139 clothianidin concentrations detected in soil collected from the field margins of conventionally

140 farmed, neonicotinoid treated oilseed rape and winter wheat fields in the UK (Range: 2.25-

141 13.3ppb and 0.41-19.1ng/g respectively; both 100\% frequency of detections) (Botias et al.

142 2015). These samples were collected in the spring, approximately 10 months post-drilling of

143 treated crops in fields undergoing conventional arable rotation. 100ppb was used as a positive

144 control. While these levels were used to replicate those present up to 40 weeks since seed

145 drilling, it should be noted that levels of 270 to $440 \mathrm{ppb}$ have been found in soil up to three

146 days after a single CLO application (Ramasubramanian, 2013). 
147 Food contamination

148 Primary waste paper sludge from a paper recycling plant (Sittingbourne, Kent) was mixed

149 with brewer's yeast at a 25:1, carbon to nitrogen ratio following methods described in Butt

150 (1993), and used as a food source (referred to hereafter as "food"). To ensure homogeneous

151 distribution of the CLO solution throughout the food, CLO stock solution was first added to

152 spring water (ASDA own brand) and yeast before thoroughly mixing in the paper waste.

153 Food was treated to the following levels: $0 \mathrm{ppb}$ (control), 1ppb, 5ppb, 10ppb, 20ppb and

$154100 \mathrm{ppb}$.

155

156 Microcosm set-up

157 Tops were removed from 180 x 4 litre plastic bottles (henceforth described as "microcosms")

158 and they were each filled with $1.5 \mathrm{~kg}$ of contaminated soil substrate. Three separate

159 experiments were set up: A - treated soil only, B - treated soil and treated food and C -

160 treated food only, with 10 replicates per treatment group in each exposure and control group.

161 Care was taken to ensure that no large air pockets were present as these could be used by the

162 worms as a refuge. The bottle opening was covered with fine plastic mesh to prevent escape.

163 Every microcosm received $70 \mathrm{~g}$ of food atop of a stainless-steel mesh $(6 \mathrm{~mm} \times 6 \mathrm{~mm})$ placed

164 on top of the soil substrate. The 720 worms were purchased from Worms Direct (Maldon,

165 Essex, UK) and all were mature with clitellum. Prior to the experiment worms had been fed

166 on leaves but all underwent a 7-day acclimatisation period where their food was swapped to

167 the paper waste and yeast mixture used in this experiment. Each microcosm housed 4 worms.

168 Experiment A received worms that were approximately 2 months older than individuals used

169 to initiate experiments $\mathrm{B}$ and $\mathrm{C}$. Microcosms were kept at $18^{\circ} \mathrm{C}$ and $50-70 \%$ relative

170 humidity, following Lowe \& Butt (2005).

171 Data collection

172 Every 4 weeks, the contents of each microcosm was emptied into clean buckets, and the

173 worms were gently washed and blotted dry. The worms from each microcosm were weighed

174 together as a group; body mass has previously been shown to be a sensitive biomarker in the

175 earthworm (Dittbrenner et al., 2010). In order to avoid additional stress to the individuals,

176 worm weight was not standardised by voiding the gut contents of individuals prior to worms

177 being weighed. The weight of food remaining on the grill was then subtracted from the 
178 starting weight each month and is henceforth described as 'food consumed'. However, it is

179 important to note that some of this food had been taken down into each burrow and stored i.e.

180 it had not actually been ingested by the worms. Cast production can be used as a proxy for

181 earthworm activity (Capowiez et al., 2010), however, casts could not be separated from the

182 food as worms had commonly cast directly into their food source. Obvious casts were

183 removed from the edges of the grill before the remaining food was weighed. The worms were

184 then placed back into the bottle with the same soil. The remaining food was discarded and

185 replaced with freshly contaminated food and any water lost through evaporation from the soil

186 (as defined by weight lost from a bottle of soil without worms) over the month was replaced

187 in order to return the soil moisture to $25 \%$ (Berry \& Jordan 2001). Each experiment ran for 4

188 months in total.

189 Data analysis

190 The average weight of individuals and the average amount of food consumed per worm were

191 calculated every 4 weeks for each replicate. All analyses were carried out using SPSS version

19222 (IBM Corp, 2013). Worm weights across treatment groups were compared using repeated

193 measures ANOVA when assumptions of normality (as defined by the Shapiro-Wilk statistic)

194 were met. The assumption of sphericity (as defined by Mauchly's statistic) was not met for

195 data from any treatment group, therefore Greenhouse-Geisser adjustments were made to

196 correct the ANOVA and it is this adjusted $\mathrm{p}$ value that is reported. The within-subject

197 variance of food consumed per worm was found to have significant heterogeneity and

198 therefore non-parametric Kruskall-Wallis H tests were preferred for this variable. Significant

199 effects were investigated further using pair-wise comparisons using Dunn's procedure with a

200 Bonferroni correction for multiple comparisons.

201 Survival curves were fitted to mortality data for each exposure group using the non-

202 parametric Cox's proportional hazards model (CoxPH). The CoxPH assumes proportional

203 hazards (chance of mortality) within treatment groups using control group mortality as a

204 reference. The output from this model was compared with a parametric model, alternately

205 assuming a constant hazard and a non-constant hazard with Weibull errors to ensure good

206 model fit (Rotheray, 2012). To assess the effects of treatment on mortality, a separate CoxPH

207 was fitted to compare pooled treatment groups with pooled control groups, applying any level

208 of CLO treatment on effect on survival. 
209 Results

210 Experiment A: Treated Soil

211 Neither the weight or food consumed by worms kept in treated soil and fed untreated food

212 varied significantly across treatment groups over time (weight: $F=1.231, \mathrm{D} . \mathrm{F}=11.1, \mathrm{p}=$

2130.279 , repeated measures ANOVA, food: week 4: $X^{2}(5)=10.443, p=0.064$; week 8: $X^{2}$

$214(5)=7.073, p=0.215$; week 12: $X^{2}(5)=3.817, p=0.576$; week 16: $X^{2}(5)=5.44 p=0.364$,

215 Kruskall-Wallis (Fig 1 a \& b)). Mortality was lowest in the control group across all time

216 points, with $52 \%$ of the total population remaining at week 16 (Fig 1, c). The CoxPH detected

217 a significant effect of treatment on mortality $(Z=2.348, p=0.0189)$. However, there was no

218 clear dose-response effect at higher doses (Fig 2), with worms exposed to 20ppb CLO having

219 the highest mortality ( $80 \%$ by week 16$)$.

220 Experiment B: Treated Soil and Treated Food

221 There was no significant difference in the weight of worms between treatments when

222 exposed to clothianidin in both soil and food (Fig 3, a) $(F=1.825, \mathrm{D} . \mathrm{F}=10.365, \mathrm{p}=0.062$,).

223 Analysis of food consumption revealed significant differences in consumption across

224 treatment groups over time, with generally lower consumption when exposed to higher

225 pesticide concentrations (week 4: $X^{2}(5)=29.639, p=<0.001$; week 8: $X^{2}(5)=34.876, p=$

$226<0.001$ and week 12: $\mathrm{X}^{2}(5)=11.650, \mathrm{p}=0.040$ but not week 16: $\left.\mathrm{X}^{2}(5)=8.761, \mathrm{p}=0.119\right)$.

227 Pairwise comparisons highlight significant differences between all treatment groups and

$228100 \mathrm{ppb}($ Fig 3, b) at week 4 (adjusted p: $1 \mathrm{ppb}=<0.001,5 \mathrm{ppb}=0.010,10 \mathrm{ppb}=<0.001$, and

$22920 \mathrm{ppb}=0.002$ ), and at week 8 between 100ppb and 1, 5 and 20ppb (adjusted $\mathrm{p}=<0.001$,

$230<0.001$ and .005 , respectively), there was no difference in consumption at weeks 12 and 16 .

231 Highest total mortality was observed in the 100ppb treatment group (25\% mortality) but the

232 differences in mortality between treatment groups was not significant $(\mathrm{CoxPH} \mathrm{Z}=-0.173, \mathrm{p}=$

2330.863 , Fig 3c).

234 Experiment C: Treated Food

235 There was no significant relationship between CLO concentration and weight for the worms

236 fed on treated food only $(F=1.809$, D.F $=8.870 \mathrm{p}=0.078)$. However, the amount of food

237 consumed was significantly different across treatment groups at week 4 and week $8\left(X^{2}(5)=\right.$

$23835.304, \mathrm{p}=<0.001$ and $\mathrm{X}^{2}(5)=11.241, \mathrm{p}=0.047$, respectively). Pairwise comparisons at

239 week 4 show less food being consumed in the 100ppb group than in other groups bar 20ppb 
240 (adjusted p: $1 \mathrm{ppb}=<0.001,5 \mathrm{ppb}=<0.001,10 \mathrm{ppb}=0.004$ and Control $=0.007$ ), and less food

241 consumed at 100ppb compared to $1 \mathrm{ppb}(\operatorname{adj} . \mathrm{p}=0.039)$ at week 8. Mortality in Group C (Fig

$2424 \mathrm{c}$ ) was highest in worms fed with $20 \mathrm{ppb}$ treated food (27.5\% mortality) and lowest in food

243 groups $1 \mathrm{ppb}$ and $5 \mathrm{ppb}(10 \%$ mortality). Overall, there was no significant difference in

244 mortality between treatment groups (CoxPH Z $=0.935, \mathrm{p}=1.522)$. It is notable that mortality

245 in experiments B and C was markedly lower than in experiment A which used older worms.

246 Discussion

247 Our findings suggest that at field-realistic doses, chronic exposure to clothianidin does not have a significant effect on worm weight but that contamination of food can significantly impact the amount of food consumed for up to two months after initial oral exposure, and may also increase worm mortality.

\section{Mortality}

Mortality levels for worms in experiments with treated food only, and treated food and soil suggest that CLO concentrations of $\leq 100 \mathrm{ppb}$ do not cause significant mortality above that of the control, whereas there was a significant effect of exposure to treated soil alone. We speculate that this may be because the worms in experiment A were two months older than those in experiments $\mathrm{B}$ and $\mathrm{C}$, but this would clearly require further investigation. Patterns of mortality across the three experiments were unclear as all lacked a clear doseresponse effect. Of the 13 previous studies on the effects of neonicotinoids on earthworm survival that reported $\mathrm{LD}_{50}$ values, only one studied clothianidin but used E. fetida as its study species. Wang et al. (2012) describe clothianidin as "super-toxic" to E. fetida (contact toxicity survival: $0.28 \mu \mathrm{g} / \mathrm{cm}$, soil toxicity survival: $\mathrm{LC}_{50}=6.06 \mathrm{ppm}$ ) though this level is high compared to reported field concentrations and hence the phrase may be misleading. All other studies investigated imidacloprid or thiacloprid and reported $\mathrm{LC}_{50}$ ranges from 1.5 to 25.5ppm, with a mean of 5.8 and median of 3.7ppm (Pisa et al. 2014). The longest exposure duration was 6 weeks, much shorter than the 16-week exposure used in this study. Further, 7 of those 13 studies reported lowest effective concentrations ranging from 0.7 to $25 \mathrm{ppm}$, with a mean of 4.7 and median of 1ppm (Pisa et al., 2014); all of which are concentrations that are 
271 Our study aimed to test effects of exposure to field-realistic concentrations. Overall, our data

272 suggest that chronic exposure to concentrations of clothianidin up to $100 \mathrm{ppb}$ in food and/or

273 soil have, at worst, only weak effects on mortality of L. terrestris. However, it should be

274 noted that our study involved homogeneous mixing of the CLO throughout the soil; it is

275 possible that in a real-world situation worms may come across much higher levels of

276 neonicotinoids by coming into close proximity to treated seeds or applied granules (Pisa et

277 al., 2014).

278

279

280

281

282

283

284

285

286

287

288

289

290

291

292

293

294

295

296

297

298

299

300

301

\section{Weight}

The presence of contaminants in soil may cause stress to the individual which can divert energy from reproduction, burrowing activity and growth (Pelosi et al., 2014). The use of body mass change as a biomarker is thought to be ecologically relevant, as high losses in body mass are thought to lead to negative effects on survival and reproduction (Dittbrenner et al. 2010). We found CLO to have no significant impact on body mass even over 16 weeks of exposure. Body mass in earthworms has not been used as a measured end point in experiments with CLO but comparison can be made with other neonicotinoids (Pisa et al., 2014). Three studies have monitored sub-lethal effects of imidacloprid on body mass and weight change in L. terrestris with lowest effective concentrations at $0.66 \mathrm{ppm}$ (Dittbrenner et al., 2010), 0.189ppm (Capowiez et al., 2010) and 2ppm (Dittbrenner et al., 2011), all of which are higher than the treatments used in this experiment and above those generally found in the field. Our data suggest that field realistic exposure of L. terrestris to CLO does not impact on body mass.

As guts were not voided before weighing, it is possible that differences in worm weight between treatments could be masked or exaggerated by differences in gut content, for example if anti-feedant effects at high doses reduced gut content. However, we would expect this to lead to lower apparent mass at higher doses, which was not detected.

\section{Food consumption}


302 In this study, we found CLO to have a significant negative effect on food consumption or

303 food collection for the first 2 months of the experiment in groups where both the soil and

304 food was contaminated and where only food was contaminated. We cannot discern whether

305 the worms were able to detect and were repelled by the pesticide, or whether consumption

306 reduced their subsequent appetite. A previous study with a different worm species,

307 Apporectodea spp., has shown that field-rate application of CLO (applied at $0.15 \mathrm{~kg} / \mathrm{ha}$ ) can

308 retard long-term (4 months) grass clipping decomposition (Larson, Redmond \& Potter, 2012),

309 a finding which our study corroborates. Reduced decomposition could potentially have long-

310 term impacts on soil organic matter content which may be detrimental to crop growth.

311

312

An interesting feature of our data is the recovery of feeding rates towards the end of the experiment. As newly spiked food was provided every 4 weeks, this recovery is not because of a breakdown of CLO; it may be because the worms became desensitised, or because feeding inhibition was overridden by hunger. Food consumption recovered more quickly when only food was contaminated, compared to when both soil and food were contaminated, suggesting that both oral and contact exposure retards the recovery of the individual to a greater degree than oral exposure alone. Oligochaetes have been found to increase digging activity when exposed to thiamethoxam (Alves et al. 2013), so it is possible that any negative effect of exposure to CLO through treated soil is masked due to an irritant effect: a worm's energy requirement may increase as a result of elevated activity caused by irritation, which may therefore increase food consumption.

Earthworms are known to be able to distinguish pollutants in soil, though it is not known if this behaviour is due to being able to discern the biological availability of pollutants or other factors (Alves et al., 2013). Our study design meant that individuals were unable to avoid the contaminated soil, and therefore laboratory exposure duration may not be representative of a typical field exposure duration; in a field-realistic scenario the individuals might be able to move away from contaminated soil, even though full field application of neonicotinoids is the norm. For example, they may be able to burrow deeper where contamination is likely to be lower. In this respect our experimental design may exaggerate effects compared to real-world situations. On the other hand, the results from this single chemical exposure experiment may 
333 not adequately reflect the full effect of the contaminant on L. terrestris as in field conditions

334 they may often encounter multiple pesticides. Previous work on the impact of insecticidal

335 chemistries on beneficial non-target arthropods and earthworms has shown there to be more

336 significant effects from exposure to combination products than the singular components alone

337 (Larson et al., 2012).

338

339

The effects of neonicotinoid pesticides are often discussed assuming that all neonicotinoids act in the same way with regard to their target sites and their effects. However, individual neonicotinoids have been reported to have distinct binding to the nicotinic acetylcholine receptor (nAChRs) and therefore may pose differential risks to non-target organisms (Moffat et al., 2016). It would thus be unwise to assume that other neonicotinoids would have similar effects on earthworms to those that we describe for clothianidin (Moffat et al. 2016, Dittbrenner et al. 2011).

\section{Conclusion}

Our results show that chronic exposure of $L$. terrestris individuals to CLO at concentrations up to $100 \mathrm{ppb}$ has no significant long term effect on the weight of individuals but has significant negative impact on the amount of food consumed over a 2-month period. We also found some evidence of elevated mortality at higher doses in older worms. The eventual recovery of food consumption exhibited in individuals fed treated food highlights the importance of long-term chronic exposure studies; previous experiments have only tested the acute effects of neonicotinoid pesticides on L. terrestris, and have tended to use very high doses that may not commonly occur in the field. Although we cannot rule out negative effects on worms over longer periods, when in the immediate vicinity of treated seeds, or from combined exposure to neonicotinoids and other pesticides or stressors, our results suggest that exposure to soils and foodstuffs contaminated with field-realistic levels of CLO does not have lasting harmful effects on the growth or survival of younger $L$. terrestris individuals. Further work is required to investigate how worm age may influence their susceptibility to pesticides.

\section{Acknowledgements}


363 We would like to thank John Lloyd for assistance with data collection and Dr Beth Nicholls for critical reading of the manuscript.

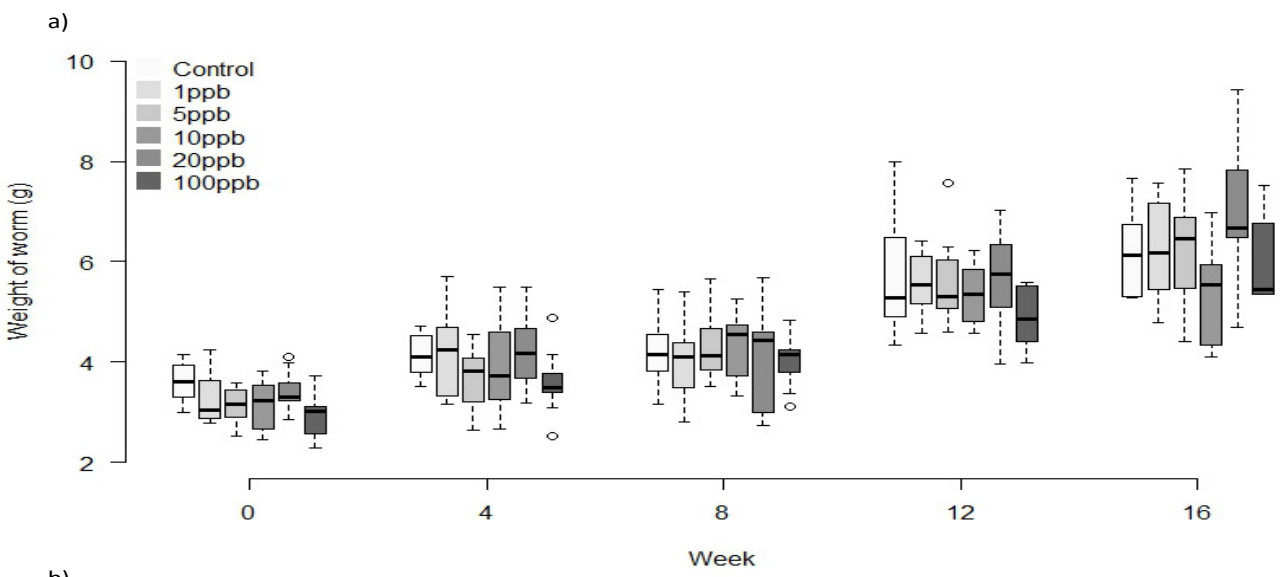

b)

Week

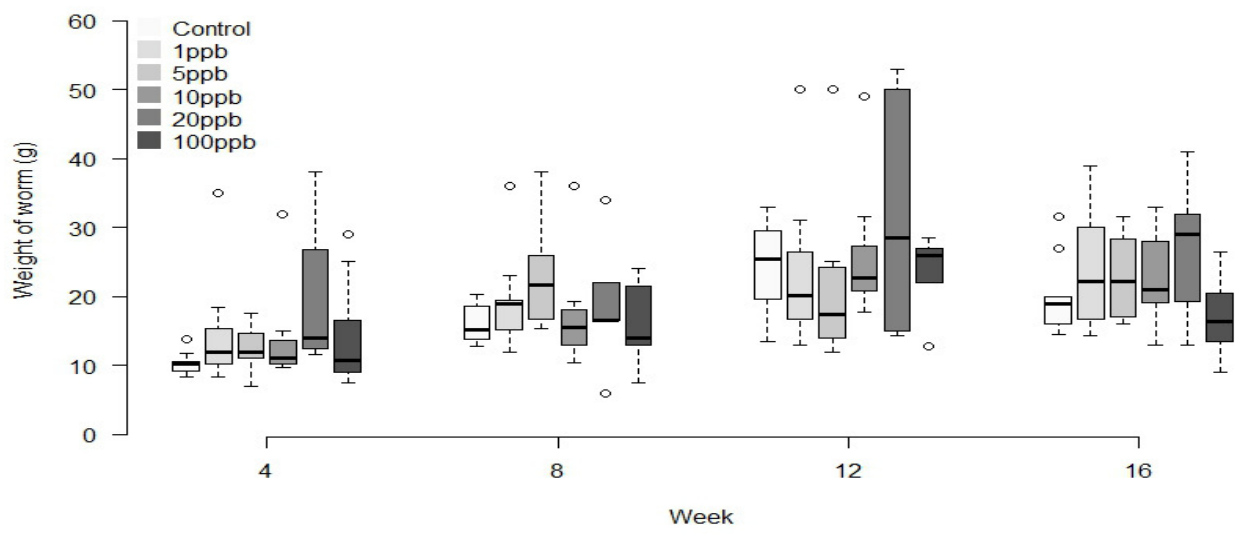

c)

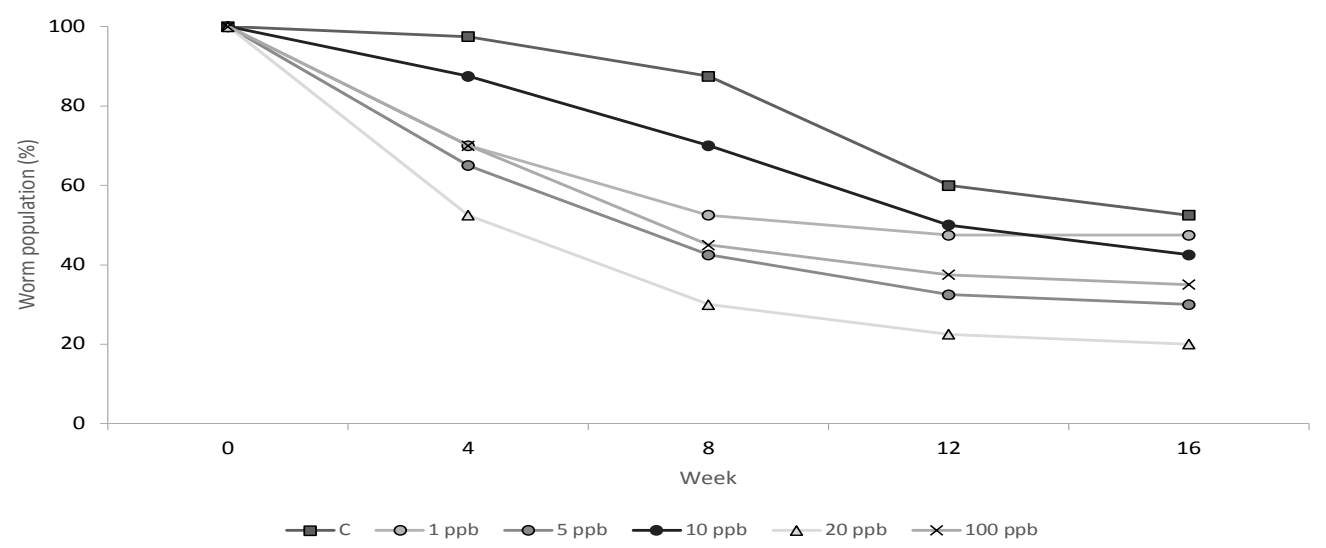

Figure 1. Experiment A: clothianidin treated soil. Changes in the mean weight (a) and mean food consumption (b) of Lumbricus terrestris individuals over time in clothianidin (CLO) treated soil containing 1, 5, 10,20,100 ppb and control. Error bars show standard error of the mean. c) Percentage of worms in relation to initial worm number. 


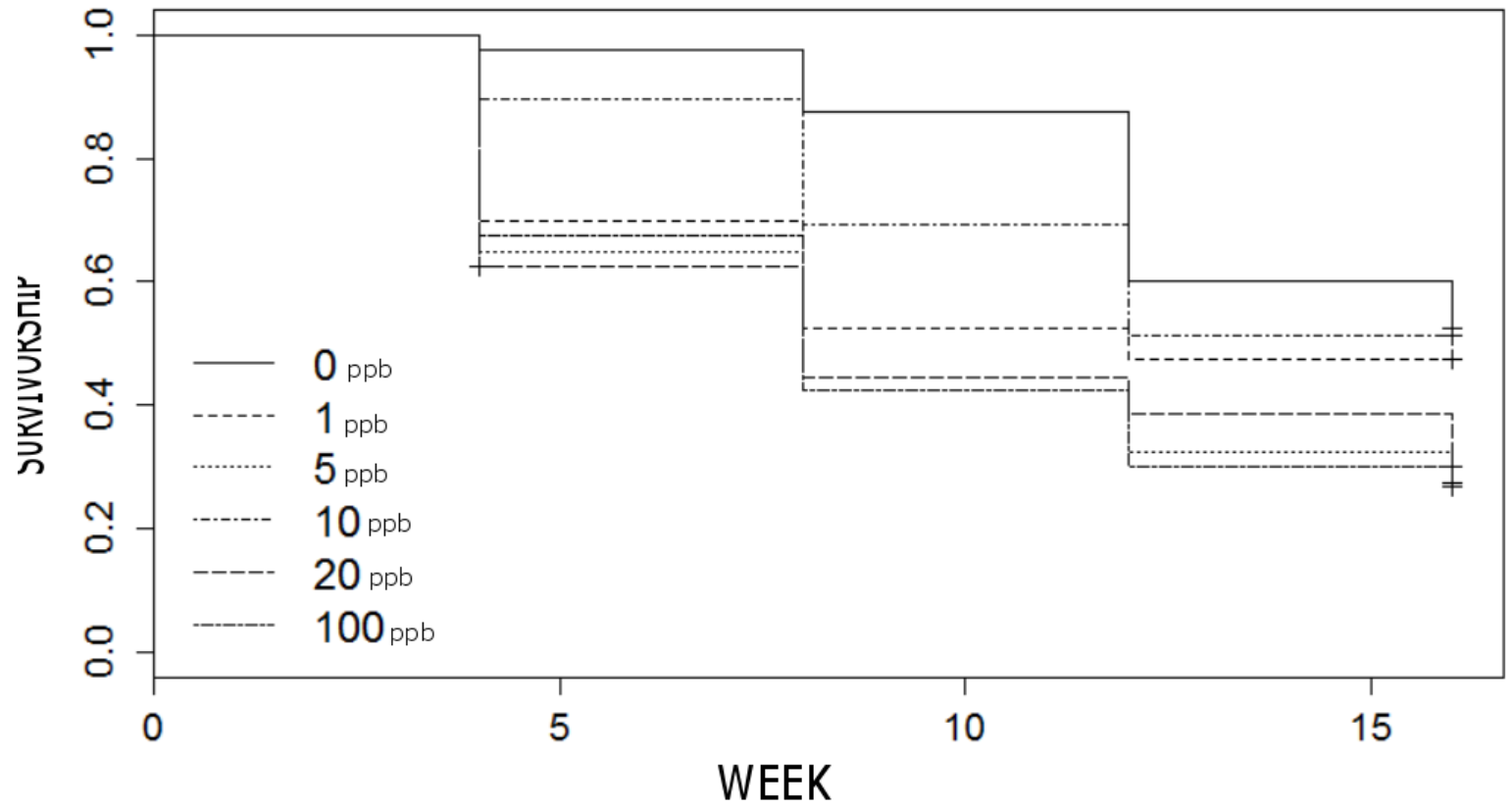

Figure 2. Experiment A: Cox proportional hazards model survival curve illustrating a significant effect of treatment on mortality $(Z=2.348, p=0.0189)$. 
375 Experiment B- Clothianidin treated soil and treated food

a)
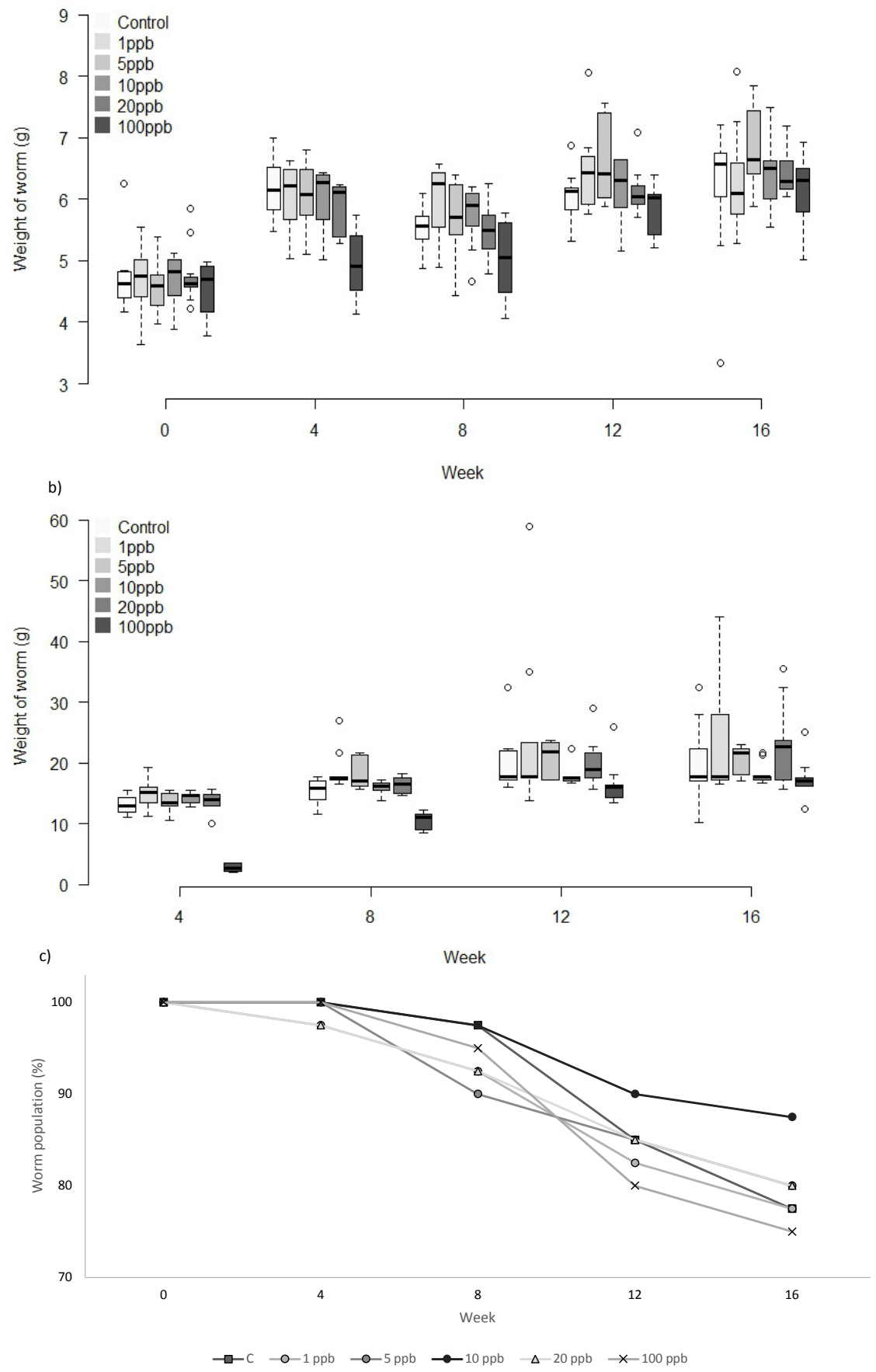

376

377

378

379

380

Figure 3. Experiment B: clothianidin treated soil and food. Changes in the mean weight (a) and mean food consumption (b) of Lumbricus terrestris individuals over time in clothianidin (CLO) treated soil provided with clothianidin treated food containing 1, 5, 10, 20, 100 ppb and control. Error bars show standard error of the mean. c) Percentage of worms remaining at each time point in relation to initial worm number. 
381 Experiment $\mathrm{C}-$ Clothianidin treated food

a)

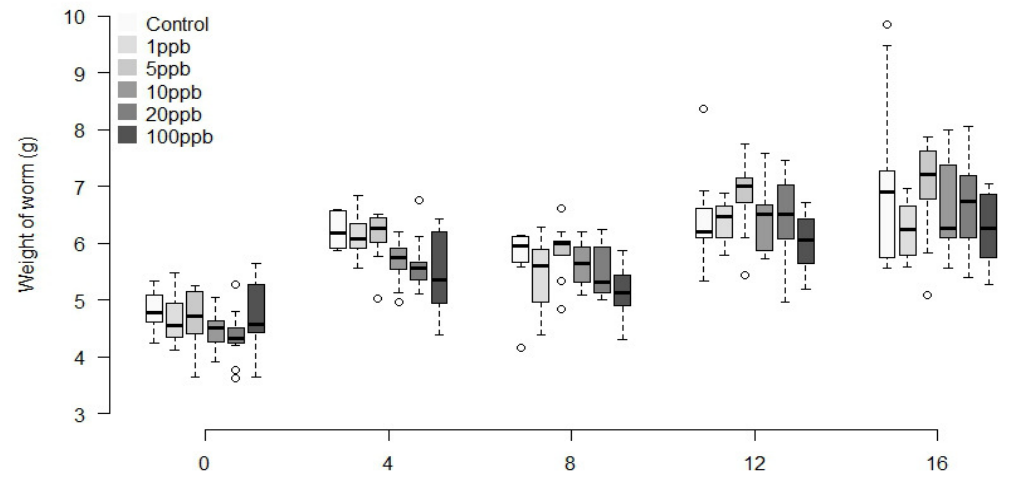

b)

Week
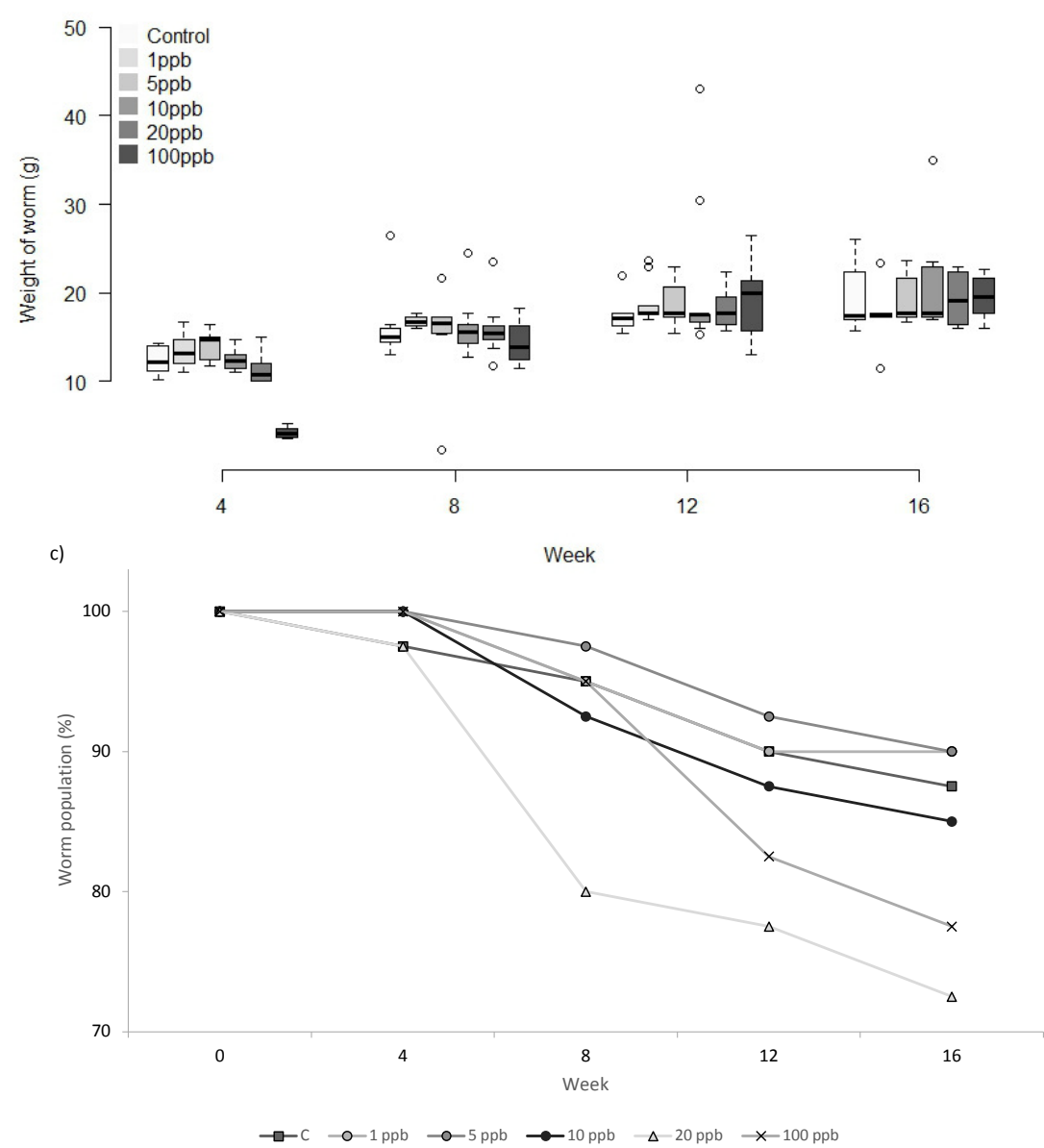

Figure 4. Group C: clothianidin treated food. Changes in the mean weight (a) and mean food consumption (b) of Lumbricus terrestris individuals over time in clothianidin (CLO) treated soil containing 1, 5, 10, 20, 100 ppb and control. Error bars show standard error of the mean. c) Percentage of worms remaining at each time point in relation to initial worm number. 
Alves PRL., Cardoso EJBN., Martines AM., Sousa JP., Pasini A. 2013. Earthworm ecotoxicological assessments of pesticides used to treat seeds under tropical conditions. Chemosphere 90:2674-82. DOI: 10.1016/j.chemosphere.2012.11.046.

Berry E., Jordan D. 2001. Temperature and soil moisture content effects on the growth of Lumbricus terrestris (Oligochaeta: Lumbricidae) under laboratory conditions. Soil Biology and Biochemistry 33:133-136. DOI: 10.1016/S0038-0717(00)00112-7.

Botías C., David A., Hill EM., Goulson D. 2016. Contamination of wild plants near neonicotinoid seed-treated crops, and implications for non-target insects. Science of The Total Environment 566-567:269-278. DOI: 10.1016/j.scitotenv.2016.05.065.

Butt KR. 1993. Utilisation of solid paper-mill sludge and spent brewery yeast as a feed for soildwelling earthworms. Bioresource Technology 44:105-107. DOI: 10.1016/09608524(93)90182-B.

Capowiez Y., Dittbrenner N., Rault M., Triebskorn R., Hedde M., Mazzia C. 2010. Earthworm cast production as a new behavioural biomarker for toxicity testing. Environmental pollution 158:388-93. DOI: 10.1016/j.envpol.2009.09.003.

Chagnon M., Kreutzweiser D., Mitchell EAD., Morrissey CA., Noome DA., Van der Sluijs JP. 2014. Risks of large-scale use of systemic insecticides to ecosystem functioning and services. Environmental Science and Pollution Research. DOI: 10.1007/s11356-014-3277$\mathrm{x}$.

Pesticide Usage Statistics. (2016). PESTICIDE USAGE STATISTICS - PUS STATS. [online]

Available at: https://secure.fera.defra.gov.uk/pusstats/ [Accessed 12 Dec. 2016].

Dittbrenner N., Capowiez Y., Köhler H-R., Triebskorn R. 2012. Stress protein response (Hsp70) and avoidance behaviour in Eisenia fetida, Aporrectodea caliginosa and Lumbricus terrestris when exposed to imidacloprid. Journal of Soils and Sediments 12:198-206. DOI: 10.1007/s11368-011-0437-1.

Dittbrenner N., Moser I., Triebskorn R., Capowiez Y. 2011. Assessment of short and long-term effects of imidacloprid on the burrowing behaviour of two earthworm species (Aporrectodea caliginosa and Lumbricus terrestris) by using 2D and 3D post-exposure techniques. Chemosphere 84:1349-1355. DOI: 10.1016/j.chemosphere.2011.05.011.

Dittbrenner N., Triebskorn R., Moser I., Capowiez Y. 2010. Physiological and behavioural effects of imidacloprid on two ecologically relevant earthworm species (Lumbricus terrestris and Aporrectodea caliginosa). Ecotoxicology (London, England) 19:1567-73. DOI: $10.1007 / \mathrm{s} 10646-010-0542-8$.

Givaudan N., Wiegand C., Le Bot B., Renault D., Pallois F., Llopis S., Binet F. 2014. Acclimation of earthworms to chemicals in anthropogenic landscapes, physiological mechanisms and soil ecological implications. Soil Biology and Biochemistry 73:49-58. DOI: $10.1016 /$ j.soilbio.2014.01.032.

Goulson D. 2013. REVIEW: An overview of the environmental risks posed by neonicotinoid insecticides. Journal of Applied Ecology 50:977-987. DOI: 10.1111/1365-2664.12111.

Hallmann CA., Foppen RPB., van Turnhout CAM., de Kroon H., Jongejans E. 2014. Declines in insectivorous birds are associated with high neonicotinoid concentrations. Nature 511:341343. DOI: 10.1038/nature13531.

IBM Corp. Released 2013. IBM SPSS Statistics for Windows, Version 22.0. Armonk, NY: IBM Corp.

Jeschke P., Nauen R., Schindler M., Elbert A. 2011. Overview of the Status and Global Strategy for Neonicotinoids. Journal of Agricultural and Food Chemistry 59:2897-2908. DOI: 
dx.doi.org/10.1021/jf101303g.

Jones A., Harrington P., Turnbull G. 2014. Neonicotinoid Concentrations in Arable Soils After Seed Treatment Applications in Preceding Years. Pest management science. DOI: 10.1002/ps.3836.

Larson JL., Redmond CT., Potter DA. 2012. Comparative impact of an anthranilic diamide and other insecticidal chemistries on beneficial invertebrates and ecosystem services in turfgrass. Pest Management Science 68:740-748. DOI: 10.1002/ps.2321.

Lowe CN., Butt KR. 2005. Culture techniques for soil dwelling earthworms: A review. Pedobiologia 49:401-413. DOI: 10.1016/j.pedobi.2005.04.005.

Moffat C., Buckland ST., Samson AJ., McArthur R., Pino VC., Bollan KA., Huang JT-J., Connolly CN. 2016. Neonicotinoids target distinct nicotinic acetylcholine receptors and neurons, leading to differential risks to bumblebees. Scientific Reports 6:1-10. DOI: 10.1038/srep24764.

Nuutinen V., Butt KR., Jauhiainen L. 2011. Field margins and management affect settlement and spread of an introduced dew-worm (Lumbricus terrestris L.) population. Pedobiologia 54:S167-S172. DOI: 10.1016/j.pedobi.2011.07.010.

Pelosi C., Barot S., Capowiez Y., Hedde M., Vandenbulcke F. 2014. Pesticides and earthworms. A review. Agronomy for Sustainable Development 34:199-228. DOI: 10.1007/s13593-0130151-z.

Piiroinen S., Botías C., Nicholls E., Goulson D. 2016. No effect of low-level chronic neonicotinoid exposure on bumblebee learning and fecundity. PeerJ 4:e1808. DOI: 10.7717/peerj. 1808 .

Pisa LW., Amaral-Rogers V., Belzunces LP., Bonmatin JM., Downs C a., Goulson D., Kreutzweiser DP., Krupke C., Liess M., McField M., Morrissey C a., Noome D a., Settele J., Simon-Delso N., Stark JD., Van der Sluijs JP., Van Dyck H., Wiemers M. 2014. Effects of neonicotinoids and fipronil on non-target invertebrates. Environmental science and pollution research international 22:68-102. DOI: 10.1007/s11356-014-3471-x.

Ramasubramanian T. 2013. Persistence and Dissipation Kinetics of Clothianidin in the Soil of Tropical Sugarcane Ecosystem. Water, Air, \& Soil Pollution 224:1468. DOI: 10.1007/s11270-013-1468-6.

Rotheray, E. (2012). The ecology and conservation of endangered saproxylic hoverflies (Diptera, Syrphidae) in Scotland. Ph.D. University of Stirling.

Sherlock, E. (2012). Key to earthworms of the UK and Ireland. 1st ed. Telford: Field Studies Council, p.39.

Tiwari RK., Singh S., Pandey RS., Sharma B. 2016. Enzymes of Earthworm as Indicators of Pesticide Pollution in Soil. Advances in Enzyme Research 4:113-124. DOI: 10.4236/aer.2016.44011.

Tomlin AD. 1992. Behaviour as a source of earthworm susceptibility to ecotoxicants. In: GreigSmith PW, Becker H, Edwards PJ, Heimbach F (Eds.). Ecotoxicology of Earthworms. Intercepet, Hants, pp. 116-125.

Tu C., Wang Y., Duan W., Hertl P., Tradway L., Brandenburg R., Lee D., Snell M., Hu S. 2011. Effects of fungicides and insecticides on feeding behavior and community dynamics of earthworms: Implications for casting control in turfgrass systems. Applied Soil Ecology 47:31-36. DOI: 10.1016/j.apsoil.2010.11.002.

Volkov EM., Nurullin LF., Nikolsky E., Vyskocil F. 2007. Miniature excitatory synaptic ion currents in the earthworm Lumbricus terrestris body wall muscles. Physiological research / 
480

481

482

483

484

Academia Scientiarum Bohemoslovaca 56:655-8.

Wang Y., Wu S., Chen L., Wu C., Yu R., Wang Q., Zhao X. 2012. Toxicity assessment of 45 pesticides to the epigeic earthworm Eisenia fetida. Chemosphere 88:484-491. DOI: 10.1016/j.chemosphere.2012.02.086. 